University of Washington Tacoma

UW Tacoma Digital Commons

SIAS Faculty Publications

School of Interdisciplinary Arts and Sciences

8-12-2017

\title{
Consejos as a Family Process in Transnational and Mixed-Status Mayan Families
}

Rachel M. Hershberg

University of Washington Tacoma, rmhersh@uw.edu

Follow this and additional works at: https://digitalcommons.tacoma.uw.edu/ias_pub

\section{Recommended Citation}

Hershberg, Rachel M., "Consejos as a Family Process in Transnational and Mixed-Status Mayan Families" (2017). SIAS Faculty Publications. 816.

https://digitalcommons.tacoma.uw.edu/ias_pub/816

This Article is brought to you for free and open access by the School of Interdisciplinary Arts and Sciences at UW Tacoma Digital Commons. It has been accepted for inclusion in SIAS Faculty Publications by an authorized administrator of UW Tacoma Digital Commons. 


\section{Consejos as a Family Process in Transnational and Mixed-Status Mayan Families}

This article describes a constructivist grounded theory study about cross-border relationships within Mayan families divided between the United States and Guatemala. Nine families participated, and each included a U.S.-based undocumented migrant parent and a Guatemala-based adolescent and caregiver. Findings pertaining to the family process of consejos-defined as a communication practice in Latino families wherein older family members pass on conventional wisdom to younger family members-are discussed. Although consejos has been identified as an important cultural practice in Latino families, it has rarely been examined in Mayan families or explored as an important aspect of transnational family relationships. Findings suggest that for some transnational and mixed-status Mayan families, consejos has become an important family process and a way in which migrant parents maintain a presence in their children's lives despite being physically separated. Implications for future research with transnational migrant families, and Mayan families in particular, are discussed.

Approximately 11.7 million undocumented migrants in the United States are part of mixed-status families, which typically include

School of Interdisciplinary Arts and Sciences, University of Washington Tacoma, 1900 Commerce Street, Box 358436, Tacoma, WA 98402 (rmhersh@uw.edu).

Key Words: family process, grounded theory, migrant families, transnationalism. undocumented migrant parents and U.S.-citizen children (Brabeck, Lykes, \& Hunter, 2014). Many of these mixed-status families are also transnational families because they include relatives in origin nations to whom migrants are emotionally connected despite physical separation (Zentgraf \& Stoltz Chinchilla, 2012). These transnational and mixed-status families often experience strains in family relationships because of the heightened stress from threats of detention and deportation, a lack of opportunity for increasing economic and social capital with which to support the entire family, and the separation across borders (e.g., Brabeck et al., 2014; Zentgraf \& Stoltz Chinchilla, 2012). It is important to note that millions of families experience separation as a result of unprecedented rates of migration in the $21 \mathrm{st}$ century. Thus, many children in origin nations grow up with some expectation of separation and some level of adaptability (Hershberg \& Lykes, 2015).

Nevertheless, few studies have examined relationships within these families while attending to transnational and mixed-status dimensions of family life. This limitation is due in part to a lack of research with family members in the multiple countries across which their entire family unit is divided (Mazzucato \& Schans, 2011). Thus, little is known about cross-border family relationships from the perspectives of the various participating family members despite research confirming that transnational family members do maintain ties to one another (e.g., Mazzucato \& Schans, 2011; Sørensen \& Vammen, 2014). Moreover, little is known about the processes 
or strategies families use to maintain such ties over time.

Accordingly, between June 2010 and 2012, I examined the processes through which a small sample of transnational and mixed-status Mayan families-divided between the United States and the Quiche region of Guatemala for an average of 10 years - developed and maintained ties. Through employing a constructivist grounded theory (GT) approach and an integrative theoretical framework (Charmaz, 2006), I identified the following three main transnational family processes in which participants engaged: sending and receiving remittances, communicating across borders, and giving and receiving consejos (defined most frequently in the literature as a form of communication within Latino families in which conventional wisdom is passed down from an older to a younger family member; e.g., Delgado-Gaitan, 1994; López \& Vázquez, 2006).

This article reports findings from this larger study pertaining to the giving and receiving of consejos. As described later, although consejos has been defined as an important cultural communication practice in Latino families, it has rarely been examined in Mayan families or explored as an important aspect of transnational family relationships. This article suggests that for some transnational and mixed-status Mayan families, consejos has also become an important aspect of parenting from afar and a way in which migrant parents in the United States strive to maintain a presence in their Guatemala-based children's lives despite being physically absent. This article also posits that Mayan migrant parents consciously alter the ways in which they communicate with their children in origin countries because they are separated from them; they give them consejos but not the mandados (mandates/directives) that may be more typical of Mayan parent-child relationships.

The constructivist GT approach, through which consejos as a transnational family process was identified, is described next. The theoretical framework and literature that guided the larger study from which this article developed are then reviewed, followed by a detailed description of the GT methods that were implemented. Finally, the findings that pertain to consejos in transnational and mixed-status Mayan family relationships are presented.

\section{A Constructivist Approach to Grounded THEORY}

Constructivist GT is a qualitative method that is often used to contribute to theory-building regarding a topic about which little is known (Charmaz, 2006). A constructivist approach emphasizes that reality is socially constructed and locates individuals in distinct historical and cultural contexts that influence the meanings they make of their lives, including their daily perceptions of events or experiences (Mills, Bonner, \& Francis, 2006). This approach also allows one to examine structural conditions that may influence individuals' lives—such as U.S. immigration policies and practices or Guatemala's socioeconomic context. It also allows one to examine the meanings participants make of these conditions (see Charmaz, 2006).

In constructivist GT, clear guidelines are provided to aid the researcher in recognizing when understandings, hypothesizing, and theorizing are coming from the researcher's own experiences, values, culture, or training, which may differ from participants' and lead the researcher away from the data. Constructivist GT also includes procedures for systematically constructing analytic concepts through the analysis of data (e.g., Charmaz, 2006; Strauss \& Corbin, 1998). These guidelines directed this study's methods.

\section{Research With Transnational and Mixed-Status Families}

\section{Integrative framework}

To understand the complex contexts in which participants were living and how these could influence their family experiences, an integrative framework drawing from transnational, family systems, and sociolegal theories also guided the larger study. Transnationalism has been defined as the processes that link the global and the local (Sørensen \& Vammen, 2014). Transnational scholarship suggests that in the United States and internationally, migrants and their children are often (but not always) participating in social, economic, religious, political, cultural, and familial processes that extend borders or occur in both origin and host societies (Sørensen \& Vammen, 2014; Zentgraf \& Stoltz Chinchilla, 2012). Family systems theory provides a framework for focusing on dynamic interactions, processes, and relationships within families. A key 
tenet of this perspective is wholeness, which states that family members are more appropriately viewed as interrelated parts of a family unit than as individuals acting in isolation; any change in one family member is understood to influence the entire family unit (Becvar \& Becvar, 2006). Sociolegal theories also provide a framework for conducting research with families and particularly mixed-status families. Sociolegal theories emphasize that legality or illegality are constructions applied to members of migrant populations in host societies that are produced by political forces and social interactions (Coutin, 2000). Despite their constructed nature, such states are believed to impact individual and familial well-being.

\section{Review of research}

The integrative framework that guided the larger study complements the aforementioned wholeness property. When applying this tenet to the experiences of transnational and mixed-status families, it becomes clear that the heavily guarded U.S.-Mexico border as well as limited employment opportunities for migrants in the United States, for example, influence migrants' well-being but also the well-being of their relatives in origin nations (Hershberg \& Lykes, 2015; Zentgraf \& Stoltz-Chinchilla, 2012). Specifically, recent research with migrants has shown that their experiences in the United States have been found to contribute to their prolonged stays in the United States and, thus, to their prolonged separation from children and other relatives in origin countries (e.g., Dreby, 2010; Hershberg \& Lykes, 2015; Zentgraf \& Stoltz Chinchilla, 2012).

Importantly, some of the research with these transnational and mixed-status families points to the following two cross-border processes that appear to lessen the psychosocial challenges of separation for family members: the sending and receiving of money and other goods from U.S.-based migrants to relatives in origin countries (i.e., remittances) and regular communication (e.g., Dreby, 2010; Zentgraf \& Stoltz Chinchilla, 2012). Research has shown that among those migrants who are able to find work are some who remit as much as $30 \%$ of their annual incomes to relatives in origin countries (Castañeda, 2012; Hagan, Eschbach, \& Rodriguez, 2008). In addition to providing daily sustenance and educational opportunities for relatives in origin nations, some scholars suggest that remittances from parents in host countries become "the currency of transnational love; [the] ... only means through which parental presence can cross international boundaries" (Horton, 2009, p. 38).

Cross-border communication has also been found to be essential to sustaining cross-border familial relationships (e.g., Bacigalupe \& Lambe, 2011; Parreñas, 2005). Bacigalupe and Lambe (2011) explained that through new international communication technologies, such as texting and Skype, transnational family members are able to communicate more regularly and through communicating to take part in each other's lives. Dreby (2010) found that multiple family members, including Mexican fathers in the United States, use communication to engage in cross-border relationships. Dreby (2010) emphasized the practical purposes of communication, noting that it was used to check in about remittances and make sure everyone in the family was well.

Other scholarship has focused on the emotional dimensions of communication for migrant parents. Mothers from the Philippines and Central America described feeling closer to their children when they communicated with them more regularly (Menjívar \& Abrego, 2009; Parreñas, 2005). Moreover, regular communication reportedly assuaged mothers' worries about their children's daily well-being. Recent research also has suggested that communication for fathers in the United States may have a similar affective dimension to it: Fathers feel more connected to their children when they frequently communicate with them (Montes, 2013).

One limitation of research on cross-border communication within transnational families is that it continues to focus primarily on data collected from migrants in the United States without taking into consideration how relatives in origin countries view such communication. In addition, what these communication practices entail (e.g., what parents and children talk about, how that might change throughout the migration process) has rarely been examined.

More information about the nature of communication practices within migrant families can be found, however, in education research with Latino families in the United States. Some of this research has focused in particular on the cultural facets of communication practices. Several of these studies have demonstrated 
the importance of consejos in Latino families. Delgado-Gaitan (1994) described consejos as a cultural dimension of communication within Latino families that is "sparked with emotional empathy and compassion as well as familial expectation and inspiration" (p. 300). According to Delgado-Gaitan, consejos are used not only for practical purposes (such as to advise one's children about the importance of academics) but also to convey love and emotion.

In her work with Mexican families in the United States, Valdés (1996) also described consejos as culturally specific knowledge that had an educational purpose and as often consisting of "spontaneous homilies designed to influence behavior and attitudes" in one's children and/or grandchildren (p. 125). López and Vázquez (2006) similarly wrote about how Latino parents in the United States use consejos to communicate with and teach their children life lessons, including about the importance of receiving a good education and working hard.

Together these studies evidence that consejos are an important part of parenting for Latino parents in the United States. Moreover, this scholarship suggests that Latino parents view giving consejos to their children as an essential parenting practice that also enables them to guide their children and to be involved in their education and development more generally.

Although consejos have rarely been examined in research with Mayan families, some Mayan writers have also indicated that consejos are an important part of Mayan life. Mayan poet Xiquín wrote about how women and particularly elderly women in Mayan families are the keepers of culture and pass it down to the next generation through consejos (Krogstad, 2015). She wrote that Mayan homes are typically intergenerational homes where "parents teach their children and elders give advice to all the family" (Xiquín, 2008, p. 72). She also wrote about the importance of the oral tradition generally in Mayan families, of which consejos are a part: "The practice of the oral tradition has been necessary in everyday life and in our way of life. It is how these things are transmitted from generation to generation throughout time" (Xiquín, 2008, p. 40).

Similarly, Carey, a historian, suggested that for some Maya, oral traditions are the way in which elders pass on historical lessons to the next generation: "Elders teach younger generations about their history because it is relevant to their lives today. ... [O]ral histories serve as a guide, not just of the past but also of the present and future" (Carey, 2001, p. 249). How these oral traditions, and consejos in particular, play a part in relationships for Mayan families that are transnational and mixed-status, however, has infrequently been investigated.

\section{Current Investigation}

To address some of the gaps in the research described previously, this article explores the use of consejos within transnational and mixed-status Mayan families. The larger study from which this article developed sought to address two research questions. First, how do undocumented Maya K'iche' parents based in the United States, their children in Guatemala, and their children's caregivers in Guatemala maintain ties across borders and during varying periods of separation? Second, how do these families understand and make meaning of family separations? Findings pertaining to consejos as a transnational family process corresponds to the first research question (for additional study information, see Hershberg \& Lykes, 2015). Before presenting these findings, the methods of the larger study are described to provide the context for this investigation, beginning with background information about the Maya.

\section{Method}

\section{Research Context: Undocumented Migration of the Maya}

Participants in this investigation are all part of Mayan families and communities divided between the northeastern United States and the Quiche region of Guatemala. Although the Maya consist of a substantial portion of the one million Guatemalan migrants currently living in the United States (exact numbers are unknown; Loucky, 2012), their migration experiences predate and were exacerbated by nearly four decades of armed conflict in Guatemala. The conflict, referred to as la violencia (the violence), ended with the signing of peace accords by the Guatemalan government and the Guatemalan National Revolutionary Unity in December 1996. During this conflict, more than 620 massacres and 200,000 murders or "disappearances" occurred that were linked to the Guatemalan government. Of the victims, $83 \%$ were indigenous Maya (Grandin, Levenson, \& Oglesby, 2011). 
Research suggests that poverty, drug trafficking, racism, ongoing gang and gender violence, and a culture of impunity in Guatemala are part of the aftermath of this conflict (Grandin et al., 2011). These factors continue to push an ever-increasing number of Maya to the United States, including girls and women in search of asylum (Lykes \& Hershberg, 2015). Although increased militarization of the U.S.-Mexican border was implemented to deter unauthorized migration to the United States, the Maya (and Guatemalan migrants more generally) continue to arrive without authorization. This increased militarization of the border has also contributed to an increase in the violence experienced while traveling to the United States and migrants' decisions to stay in the United States for longer durations (Brabeck et al., 2014; Lykes \& Hershberg, 2015). These experiences create additional challenges for family in the United States and Guatemala.

\section{Conducting Research in the United States and Guatemala Through the Migration and Human Rights Project}

Examining these family challenges, as well as the human rights violations experienced by the Maya in the United States, are two of the main goals of the Migration and Human Rights Project (MHRP). The MHRP is an ongoing, transnational participatory and action research project between the United States and Guatemala through which the larger study developed. The MHRP began in 2007 in response to an increase in deportation raids throughout the United States. Collaborators on the project include members of the transnational Maya K'iche' community in the northeastern United States and in Zacualpa (a municipality in the Quiche region of Guatemala); the Franciscan Sisters of San Antonio, who lead the social programs at the Church of the Holy Spirit in Zacualpa; and social science and law professors and students at universities throughout the United States (for more information, see Hershberg \& Lykes, 2015).

\section{Participants and Recruitment}

Participants included 34 family members across nine families. A total of 21 interviewees were based in Guatemala. Of the Guatemala-based sample, 12 interviewees were Guatemala-based adolescents (aged 11-19), and nine interviewees were caregivers who included mothers, aunts, grandfathers, grandmothers, or older brothers. The 13 U.S.-based interviewees were all undocumented migrant parents.

Six families were recruited through educational workshops led by me and additional members of the MHRP at the Faith and Joy (Fe y Alegria) middle and high schools in Zacualpa. Through these workshops, I was able to get to know adolescents whose families fit the selection criteria for this study of having at least one U.S.-based undocumented migrant parent and a Guatemala-based caregiver and experiencing separation from that parent for at least 2 years. When I identified adolescents who I thought might have an interest in participating, I contacted their Guatemala-based caregivers, described the study goals, and explained the informed consent procedures. After receiving consent from caregivers, I explained the informed consent procedures to the adolescents. I typically interviewed the adolescents first, then their Guatemala-based caregivers. When I returned to the United States, I contacted the U.S.-based relatives, described the study goals, and explained the informed consent procedures prior to conducting interviews.

Three other families had already been participating in the MHRP before the study began and agreed to participate in this investigation as well. The parents in these families assisted in arranging to meet with the Guatemala-based adolescents and caregivers during my first visits to Guatemala. During these visits, I similarly explained the informed consent procedures before conducting initial interviews. When I returned to the United States, I conducted interviews with the U.S.-based parents.

\section{Interviews}

Each interview was conducted in Spanish, audio-recorded, and then transcribed in Spanish. Throughout the interview process, I was accompanied by a local Maya K'iche' guide connected to the MHRP. This guide translated specific interview questions or responses from K'iche' to Spanish (and vice versa) when participants were more comfortable communicating in K'iche' (which occurred in only a few instances). When translating excerpts into English for documenting findings, I also consulted with a U.S.-based, Spanish-, K'iche'-, 
and English-speaking Maya K'iche' member of the MHRP. This colleague provided assistance with colloquialisms particular to the Maya K'iche'. (Translations included here from Spanish and K'iche' into English may vary in other parts of Guatemala.)

I used a similar set of semistructured interview questions with the Guatemala-based youth, caregivers, and U.S.-based undocumented migrant parents. This was because I aimed to elicit information about caregiving behaviors and relationship characteristics from each of these family members. I also aimed to elicit each of their views about deportation and family separation (as part of addressing the second research question).

The interviews with the children were typically between 45 and 60 minutes, and the interviews with the adults were between 45 and 90 minutes. The questions in the initial interviews were broad and mostly focused on what family members did to "care" for children in Guatemala from the perspectives of parents in the United States, caregivers in Guatemala, and adolescents in Guatemala (see the appendix for the Child Interview Guide in English and Spanish). These questions were open-ended so that the interviewees could lead the interview, with the hope that concepts would emerge that would inform subsequent interviews as part of the GT process. Interviewees were prompted to provide examples and stories throughout the interview and particularly when describing different caregiving behaviors.

Through analyzing initial interviews following GT procedures (Strauss \& Corbin, 1998), the interview questions became more narrow and directed. For example, after learning from interviews with the children from the first three families who participated that phone calls from one or both of their undocumented migrants in the United States were meaningful to them and were viewed as an essential part of their relationships, specific questions were included in subsequent interviews about the content of the conversations in which the children engaged with their parents and the emotions the children experienced when communicating with them. The specific questions about the frequency of phone calls were also added after the first three families were interviewed to examine whether and to what degree the frequency of cross-border communication mattered to the Guatemala-based children in participant families. Although the presence of consejos in parent-child relationships was not asked about directly in interviews, they came up repeatedly when participants described what parents did to "care for children" from afar.

In addition to these questions, the interviews with the Guatemala-based youth (who were 11-15 years old and being interviewed for the first time) began with youth being asked to draw a picture of "who comes to mind when you think of family." I also asked the youth to indicate in the drawing where each family member was based and the activities they were engaged in. Drawing is a useful method for sparking interview conversations with youth, especially when cultural and language barriers might be present (Didkowsky, Ungar, \& Liebenberg, 2010). With adults, instead of a drawing, I co-constructed a genogram of the family, indicating relatives' ages, locations, and citizenship statuses, before asking about caregiving behaviors and experiences with immigration and deportation.

\section{Data Analysis}

Throughout the research process, data were iteratively and inductively analyzed with the aim of constructing a theory or analytic concept that contributes to understandings of family processes in transnational, mixed-status Mayan families. I continuously interacted with the data following the sequential coding scheme recommended by Strauss and Corbin (1998) and the guidelines provided by Charmaz (2006). This included (a) applying open, axial, and selective codes to the data; (b) conducting theoretical sampling procedures; and (c) attending to the conditions, contexts, action or interaction strategies, and consequences that appeared to be linked to transnational family relationships for participants in this study.

Open and axial codes were used, respectively, to identify concepts of potential relevance and to begin generating more explanatory codes and categories. Selective coding was used at the conclusion of the analysis to identify the main analytic concept from the data once much of the theoretical sampling occurred. This third step allows for identifying a core category or variable that pulls the other categories and codes established earlier in the analysis together "to form an explanatory whole" (Strauss \& Corbin, 1998, p. 146; see also LaRossa, 2005). 
Theoretical sampling was used to focus on concepts that could be particularly relevant to the research questions. This procedure also enabled me to define concepts in terms of their properties, dimensions, and variations within and across interviews. By employing this procedure, I could demonstrate how concepts that emerged in initial interviews were related to concepts in subsequent interviews (LaRossa, 2005). In the first phase of data collection and analysis, for example, interviews with the children and Guatemala-based caregivers from only three families were conducted. In the analyses of these interviews, the phenomenon of cross-border communication was identified. I then specified this phenomenon in the analyses of these interviews in terms of the conditions that emerged, such as "availability of work for migrants upon arriving in the U.S." and "the presence of cell phones and cell phone towers in Zacualpa, Guatemala" when parents arrived in the United States. I also defined this phenomenon according to the actions and interactions that appeared to be related to it: I identified "calling family in Guatemala and buying calling cards to make phone calls" as actions that facilitated cross-border communication, including passing on consejos (Strauss \& Corbin, 1998). A major consequence of cross-border communication was reportedly children in Guatemala "feeling a tie is maintained because parents always call." I employed this form of theoretical sampling throughout the analysis, examining additional interviews for similar concepts and variations therein. Constant comparison methods were also used, ensuring that interviews with children were compared with interviews with caregivers and parents and to interviews with the children in other families (Strauss \& Corbin, 1998). Because I was interested in examining how transnational and mixed-status families functioned as a whole, I also made across-family comparisons. (I engaged in memo writing, reflexivity, and member checking to enhance the rigor and trustworthiness of the analysis [Charmaz, 2006; Morrow, 2005; Strauss \& Corbin, 1998]. I used memos to write about potential relationships between concepts and categories and to track the thought process used to define concepts. With a colleague, I also engaged in reflexivity processes throughout this study. Through writing and discussion, I was reminded of how the various frames I brought to this research influenced the analysis and could lead away from the data. I was also reminded of the limitations of my "insider" status despite being a part of the MHRP for several years [see Hershberg \& Lykes, 2015]. However, it was through working on the MHRP and in Guatemala before beginning this study and my consistent consultation with Mayan colleagues and participants that the trustworthiness of findings was enhanced [Morrow, 2005]. This consultation included community feedback meetings in the United States and in Guatemala with participant families and informants [e.g., teachers at Faith and Joy High School].)

\section{FINDINGS}

\section{Main Analytic Concept}

In the larger study, I developed the main analytic concept of "being present when forced to be absent" to explain how participant families maintained relationships across borders and understood and made meaning of their separations. This concept described the cross-border processes (i.e., remittances, communication, and consejos) that differently situated family members used to maintain ties to one another and the various barriers they encountered when doing so. Migrant parents most commonly reported that these processes facilitated their efforts to maintain a sustaining presence in their children's lives despite physical absences and the many sociopolitical and economic obstacles facing them, their children, and their children's caregivers. Nearly all of the participants described these latter obstacles (e.g., U.S. deportation policies and a lack of steady work in the United States and Guatemala) as forcing increasingly prolonged separations on the family. It was in this context of prolonged separation that consejos reportedly came to the fore as an important transnational family process.

\section{Consejos in Transnational and Mixed-Status Mayan Families}

In the data provided next, consejos arose in exchanges between older family members and younger family members, but not necessarily between elders in the family and younger family members. Consejos were primarily described as a main aspect of transnational parent-child relationships by both Guatemala-based adolescents and U.S.-based migrant parents when 
they were asked what the parents did to care for their children from afar. In addition, they were described as part of the caregiving processes in which Guatemala-based caregivers (who included elders, parents, and siblings) engaged.

In follow-up phone conversations with three mothers, I corroborated this interpretation of how consejos came up in participant families. Mothers reiterated that they frequently give consejos to their children during cross-border phone conversations ("pero nunca mandados" ["but never mandates/directives"]). They explained that this was because they were not physically present in their children's lives and could not observe how their children would respond to what they said on the phone. They described further that if they gave mandados to their children instead of consejos, they would not have any confidence that their children would follow these directives from afar, and they would have no way to discipline them for not following them.

Transnational fathers also explained that their children would be unlikely to follow their mandates while they were separated by borders and that giving them could jeopardize their cross-border communication and relationship more generally. One father noted that his children even rejected his consejos at times.

Previous research with adolescents in Ecuador whose parents had migrated abroad also suggested that they and their migrant parents purposely "filtered" their cross-border communication so as to keep their relationship intact. Although consejos were not mentioned in this research, the adolescents described omitting certain life details from their conversations so that their parents would not feel inclined to reprimand them (Jerves, De Haene, Enzlin, Rober, 2016, p. 16).

Insights from the participants suggested that how consejos are used in their relationships differed from the use of consejos within Latino families in the United States and perhaps from the use of consejos within Mayan families who live in the same household. These possibilities were explored and examples of consejos in the participants' relationships are provided (using pseudonyms throughout). As these findings were reviewed, some of the additional challenges within transnational and mixed-status Mayan family relationships also emerged.

Consejos in transnational parent-child relationships. Consejos were a particularly salient aspect of the parent-child relationship across participant families. In the case of 20-year-old Carlos's family, these kinds of consejos exchanges were described frequently. During a February 2011 interview in Guatemala, Carlos explained that he was only able to take on the role of caregiver at age 15 because his mother prepared him and advised him sufficiently. Carlos recalled the following:

So my mother said "I am going to leave" because, well, she had the desire to buy a house and so she went and I was totally in charge of my siblings. I was 15 when she went. But before leaving my mother left me with the life advice that I need to practice, ... how I need to act here.

In February 2012, Carlos also shared that his four siblings did behave badly at times, but consejos from their mother, Lola, in the United States mitigated the challenges Carlos experienced when reprimanding them. According to Carlos, when his siblings misbehaved or when he and his siblings experienced other issues in their household, he talked to his mother in the United States and she spoke to his siblings, and "they accept her ideas and the life advice she offers and apply them as well." Here a dialectical aspect of consejos exchanges was revealed: Carlos's siblings chose to "accept and apply" their mother's advice, suggesting that they could just as well refuse it.

It was also clear that although Carlos was "totally in charge" of his siblings, their mother still tried to parent from afar and supported his caregiving efforts. In an interview with Lola in spring 2011, she also noted that despite her presence in the United States for 5 years, her children continued to look to her for approval. Lola said: "They ask me for permission for any such thing, they call me and I give them permission." The data presented here suggested that consejos are a form of cross-border communication and a strategy through which some Mayan parents supported and wielded influence over their children despite the families' experiences of separation.

U.S.-based migrant Julia also suggested that the process of a mother giving consejos to her children across borders was a valuable aspect of transnational family relationships and could provide a significant source of support to children. Julia is in her 30s and has four children of her own. She explained that she often gave consejos over the phone to her two children in Guatemala, 
Debra and Ben, whom she has not seen in more than a decade.

In an initial interview with 15-year old Jessica in Guatemala in summer 2010, she also noted how the consejos from her transnational mother were valuable and distinct from the consejos she received from her Guatemala-based caregivers, her grandparents. According to Jessica, "If I discuss the things that are bothering me with my grandmother, she doesn't understand me, but my mother does. My grandmother, I explain to her these things, she tells me 'I don't understand,' I prefer the decision of my mother."

Similarly, when summarizing what her mother did to care for her from the United States, Jessica noted the following: "What she does is give us life advice, send money, and call the house every week."

Jessica, as described previously, consistently maintained transnational communication with and received consejos from her mother. Jessica's father reportedly abandoned the family when Jessica's younger sister Yesenia was born, which meant that they were not communicating or receiving consejos from him. However, seven of the other eight families had fathers in the United States, and each appeared to be communicating and giving consejos to their children in Guatemala.

According to transnational father Cesar, to care for his children through the phone, and especially his oldest, Leopold, he offered consejos. He described these consejos in the following way:

I say do not leave school. Continue with your studies. While I am able, I am going to continue [to support them] so they can continue studying. Sometimes he [Leopold] doesn't want to but I say why? Like me, what happened to me, [to be lacking an education] it's not easy, it's very hard for me. For this I say study study, [in the future] you can look for your wife, you can be equals, in this time period, you can be well educated the two of you. It will be easier to live, I say. And all of this this, it's like this.

During a February 2012 visit to Guatemala, Leopold confirmed that he had graduated from high school and was continuing with his university studies, following his father's consejos. In this example from Cesar and Leopold, it was clear that with consejos, Cesar advised Leopold to make good decisions, decisions Cesar believed would significantly influence his life. Because Cesar grew up without an education, he believed he knew the difference an education could make in one's life. He drew from his own life experience to guide his child's actions, despite Cesar living in the United States for more than a decade, while Leopold and his other two sons grew up in Guatemala.

U.S.-based migrant fathers Antonio and Miguel also discussed the consejos they offered their children on the phone. Antonio said, "Sometimes the children fight like this, this sister with her brother, and sometimes they are bad to their mother. So I tell them they have to do what the mother says." Antonio's daughter Marianna also noted that her father "Says continue studying, continue moving forward, and with your mother, do what she says. My father tells me this, like this we talk." Although the consejos Marianna described seemed closer to directives than the other examples provided, the same intent that was present in Lola and Cesar's use of consejos, of parents trying to wield some influence over their children's behaviors and keep the peace in some way, was evident. It was also clear that Antonio, similar to Cesar, used consejos to encourage his children to study and move ahead.

Transnational father Miguel imparted similar consejos to his children in Guatemala. He and his wife Julia stated that they realized that because they were far away they could try to give their children advice but they could not make demands (mandados) of them because they were not there to regañar ("to reprimand") their children if they did not listen. With this explanation, the limited power that U.S.-based parents have over their children's actions and behaviors was evident. Marlon admitted to this in his interview as well, noting that he also tried to advise his adolescent children, Saira and Julio, from the United States, but that his children did not respond well to this parenting effort. He offered this example of the difficulties he encountered when trying to maintain a tie to his children:

Yes, it is difficult. Sometimes I try to chat with them, I try to give them some life advice-because the grandmother told me they are rebellious-so I try to give them this guidance, but in these cases, when I begin advising them that they "should not disrespect their grandfather and they should work hard and help their grandfather because there are many vices over there," they get angry with me and sometimes they throw the phone, they don't listen. 
Here again, the dialectical nature of the consejos exchanges was evident. Parents might consciously try to parent their children through consejos, but they could not control how their children would respond.

Finally, parents also described using consejos to try and protect their children from afar. Julia described using consejos to protect her daughter, Debra, from some of the violence in Guatemala that both predated and was exacerbated by the war:

I tell her: "don't get too close to the Ladino people because you don't know what they are thinking about you ..." and she asks me sometimes "why?" and I say "because of what they did to us."... I don't know how they are now but way before, I saw how they were very violent."

Although elders were described as passing on their history to the next generation through consejos (Xiquín, 2008), in this example, it was a migrant parent in her 30 s who used consejos to protect her daughter, and simultaneously, to share what she viewed as lessons from history that were relevant to the present sociopolitical context.

Consejos between Guatemala-based caregivers and Guatemala-based adolescents. The experience described by Marlon and corroborated by his mother-in-law, Sabina, was the strongest example of an adolescent in Guatemala rejecting efforts made by his or her undocumented migrant parents in the United States to be present in their children's lives through communication and consejos. It also suggested that despite some parents' claims that they only gave consejos and not directives on the phone, the children in Guatemala might not perceive a strong distinction between the two. In addition, even though some parents appeared to view giving consejos to their children in Guatemala as a way to show their affective ties to their children, the interviews suggested that the children in Guatemala might not appreciate this effort or interpret it in the same way.

Sabina shared her belief that her grandson Julio's behaviors, and his outright rejection of his parents' efforts to communicate with him and give him consejos, were connected to the anger he feels toward his parents for leaving him in Guatemala at a young age. Sabina also explained, however, that Julio acted out and was "muy rebelde" ("very rebellious") in their relationship as well. According to Sabina, Julio often rejected her consejos, and when she attempted to discipline him physically "he hits [her]." With this additional example, it became clear that this family was experiencing moments of tension in their transnational relationships and in the relationship between the Guatemala-based adolescent and caregivers.

The interviews with members of other transnational families also suggested that the adolescents in other participant families displayed similar rebellious attitudes at times. Debra, for example, expressed to her mother Julia that she was "bored" with the consejos from her grandmother. According to Julia, Debra's grandmother and caregiver "gives her consejos so frequently that they bore her. The grandmother is so much older; there is a big age difference and she is from a different generation. Sometimes this creates problems between them."

From the examples of Julio and Debra, it was evident that the migration of one's parents can have consequences on the relationships between family members in a transnational, mixed-status family, despite the U.S.-based parents' attempts to maintain ties across borders and a presence in their children's lives. There were also tensions in the relationships between alternative caregivers and the children in their care, which surfaced through examples of children resisting and rejecting the consejos from caregivers in Guatemala. Important to note, however, was that in most cases, the youth reported that the consejos offered from their Guatemala-based caregivers were valuable to them.

Ruben, a 14-year-old, described the caregiving efforts of his older brother Mani in the following way: "He attends all the meetings at school, he goes to all of the meetings, and he gives us life advice as well." Also, 12-year-old Yesenia also confirmed that she received many consejos from her grandparents (Veronica and Teodor) and from teachers. Carlos also explained that for the siblings in his care, he tried his best to advise them despite his lack of experience.

I try to complete the two functions of a mother and a father but I don't have this experience. I am a brother to them, not a father, so I don't have this experience of solving their problems. But I say [to them] everyone has their dreams to live by. If 
you have your dreams I will help you reach your dreams. You have to study and be a good example for society.

From Carlos's narrative, it was apparent that Guatemala-based caregivers, including grandparents and older siblings, also used the strategy of giving consejos even when they felt ill equipped to do so.

The variety of incidents reviewed here demonstrated that consejos, in some form, were viewed as an important parenting strategy by U.S.-based migrant parents and Guatemala-based caregivers and adolescents in Mayan families. The adolescents described fathers and mothers in the United States and caregivers in Guatemala as attempting to offer them consejos despite the family being reconstituted and separated by borders for many years. Consejos from parents in the United States often served to guide their adolescents in Guatemala, especially when their adolescents were in charge of their own siblings and, at times, overwhelmed with their caregiving duties. When Guatemala-based caregivers, including mothers, grandmothers, and brothers, tried to steer the children in their care in the right direction through providing meaningful life advice, developmental factors and other contextual strains also appeared to influence these exchanges.

\section{Discussion}

Despite the increase in transnational and mixed-status families around the globe, most research has not explored how these complex families function and maintain ties across borders from the perspectives of multiple family members (Sørensen \& Vammen, 2014). Moreover, the Maya from Guatemala are part of a growing group of migrant families in the United States, yet family studies scholarship has infrequently attended to their family experiences (Loucky, 2012).

Accordingly, this study aimed to contribute to research about transnational and mixed-status families in general and to research with Mayan families in particular. Through exploring family processes within these families, consejos were identified as an important transnational family process and perhaps as an important parenting process within Mayan families more generally. Although consejos have been identified as an important family process in research with Latino families in the United States (Delgado-Gaitan, 1994; López \& Vázquez, 2006; Valdés, 1996) and as a means through which Mayan elders pass on history to the next generation (Xiquín, 2008), they have rarely been pointed to as an important aspect of transnational parenting and communication for migrant families in general and for Mayan families specifically. That consejos appeared so prominently in participants' narratives supports scholarship suggesting that the Maya, too, identify consejos as an important aspect of family life for family members who live together, but also for those who live apart.

Moreover, these data showed that in the context of physical separation, parents consciously use consejos to have a presence in their children's lives and wield some influence over their behaviors instead of the mandados they may have relied on when they were living in the same household. There is some evidence to suggest that transnational Mayan parents view mandados as an insufficient parenting strategy in their cross-border parent-child relationships. The data presented here also suggest that Mayan parents and not only elders frequently give consejos to their children. It is also possible that when elders become more involved in direct child rearing in transnational families, they more commonly give the mandados that are characteristic of parent-child relationships, just as parents opt to give consejos instead of mandados. More research should be conducted that examines just how Mayan family roles and processes, including communication processes, are renegotiated during migration.

That parents such as Julia and Marlon articulated their reasons for providing consejos to their children instead of mandados also suggests that transnational parents are very intentional about the parenting practices in which they engage from afar. That includes choosing the kinds of communication they participate in with their children. Although there is a growing body of research on parenting behaviors across cultures and about parents' reasons for engaging in specific behaviors (e.g., Bornstein, 2012), this research has rarely been extended to transnational families. The data reviewed here suggest that some cross-cultural comparisons regarding the parenting strategies and beliefs of transnational parents could be an important contribution to contemporary migration and family studies scholarship (Mazzucato \& Schans, 2011). 
Parents' descriptions of how they used consejos instead of mandados when communicating with their children also suggests that the nature of parent-child relationships may shift in some significant yet subtle ways when parents migrate and remain abroad. More research is needed to explore the emotional significance for children and parents of directives becoming a less prominent part of these relationships. It is possible, for example, that the lack of directives being sent from the United States influences children's behaviors in origin nations. Some research suggests that elderly caregivers have limited control over children in the context of transnational family separation and that the children are more likely to become involved in delinquency when parents migrate and remain abroad (Mazzucato \& Schans, 2011). There also were examples of this in the data from Sabina and Marlon regarding Julio's responses to them. These data suggest that children "left behind" are, at times, receiving less structure than is needed to facilitate their healthy development and protection (e.g., Zhao \& Yu, 2016).

As important, several adolescents in Guatemala reported receiving meaningful guidance from their elected caregivers in Guatemala, especially when their older siblings were their caregivers. Carlos and Mani's families attested to the importance of the guidance these young men were providing to their siblings while their parents remain abroad. Although Carlos described feeling ill equipped to "perform the dual functions of mother and father," he still tried his best to advise and encourage his four younger siblings, each of whom was in school and working hard to succeed during the course of this study. Thus, it is also possible that the ways in which transnational families adapt to the challenge of parental absence, even within the same migrant community, varies significantly across families (Mazzucato \& Schans, 2011).

Another important finding was that children in Guatemala appeared to exert some agency in their family relationships. Some of the adolescents appeared to resist mothers' and fathers' efforts to parent from afar by either refusing to answer the phone when parents called or by expressing their discontent with the guidance they were offered by parents who remained in the United States. Although parents and caregivers seemed upset by these children's rejections of their consejos, the fact that the children expressed their feelings to them despite their physical separation could indicate some degree of closeness in their relationships (e.g., Grotevant \& Cooper, 1998). These adolescents' behaviors also suggest that referring to them as passive victims of migration may be too simplistic a frame to use in transnational research (Sørensen \& Vammen, 2014).

In addition, the rejection of parents' consejos may indicate that when migrant parents remain in the United States for prolonged periods of time and their children grow up without them, relationship challenges will occur (Jerves et al., 2016). The research also showed that Guatemala-based children, U.S.-based migrant parents, and Guatemala-based caregivers all identified some of the same challenges in their families and were trying to address them. Guatemala-based caregivers Sabina and Carlos consulted with U.S.-based migrant parents about how to best respond to children's behaviors. Perhaps as families continue to openly communicate and rely on one another and on their family systems, some challenges will be resolved.

Transnational parent-child relationships and elected caregiver-child relationships also appear to take on some of the same kinds of challenges that adolescent-parent relationships take on when family members are in the same household. It is well known, for example, that adolescence is a time of heightened conflict between parents and children. Some level of conflict in parent-adolescent relationships is considered healthy and even predictive of positive adolescent outcomes (Grotevant \& Cooper, 1998). Perhaps such conflict is also a "normative" aspect of intimate transnational parent-child relationships? More research with transnational families is needed to examine this possibility.

Despite the tensions and challenges that became evident through the participants' descriptions of consejos in their family relationships, it was clear that love and caring were prominent aspects of the parent-child relationships and elected caregiver-child relationships within participant families. When asked what migrant parents do to "care for children," none of the children in this study said their parents do nothing to care for them. Although some of the participants described what was lacking in their family relationships, none of the family members described an absence of ties to relatives abroad. 
Moreover, in several instances, it appeared that migrant parents were also using consejos to try and protect their children from afar. Julia tried to educate her daughter, Debra, about her perception of the violence and racism Maya may still experience in Guatemala, which she connected to the violence experienced during the civil war (Grandin et al., 2011). Julia described hoping that her daughter would at least be cautious in her daily interactions, especially because Julia and her husband are in the United States. That Julia is using consejos to protect her daughter and, simultaneously, pass on her experience of la violencia and its aftermath is a departure from the notion that Mayan elders alone pass on history to the children. It is also possible that, in some Mayan communities, parents are charged with this task-whether they live in Guatemala or the United States - due to the killing of so many Maya during the genocide. More research is needed to confirm this possibility.

Finally, the children also criticized aspects of their relationships with their elected caregivers, several of whom were the surviving elders in the family. Jessica described "preferring" consejos from her mother in the United States, despite living with her grandparents for most of her life. The articulation of relationship preferences from these adolescent girls points to a closeness in transnational mother-child relationships that is sometimes underestimated in the literature (Parreñas, 2005).

\section{Implications for Future Research}

This research contributes to a growing body of scholarship on transnational family processes, but much more is needed, particularly with other indigenous communities from the global south. The descriptions of consejos provided by fathers such as Cesar, for example (e.g., "Sometimes he [Leopold] doesn't want to [study] but I say why? Like me, what happened to me, [to be lacking an education] it's not easy, it's very hard for me. For this I say study study"), mirrored descriptions of consejos from earlier research with Latino families in the United States (López \& Vázquez, 2006). The fathers in both of these studies described providing guidance to their children about pursuing an education and drew from their own experiences to pass on these lessons.

Future research should further explore the use of consejos in other Mayan communities (including from other parts of Central America and Mexico) and continue to draw from the more robust scholarship on consejos among Latinos. Although Mayan writers describe consejos and oral history as an important part of Mayan culture, few researchers (Mayan and otherwise) have examined these facets of family relationships among the Maya. More research on these processes is needed, including in regard to potential differences in their use among Mayan children and relatives living in the same place compared with those who are divided across borders.

Additional cross-cultural research should examine if other ethnic groups adapt to the challenges of family separation in similar ways. For example, do migrant parents from different ethnic groups similarly alter the forms of communication in which they engage with their children when they live apart for many years? Do parents in other transnational communities articulate the limits of parental control in their cross-border parent-child relationships in similar ways? Addressing such questions would contribute to family studies and transnational scholarship and may provide useful information to families who have recently transnationalized or plan to.

\section{Conclusions}

Although this study sheds light on family processes within one small sample of families, the limited sample size and unique context in which participants were living precludes generalizing findings to other transnational communities. In this study, generalizability was sacrificed for initial in-depth and theory-generating data collection and analysis about a subset of Mayan transnational and mixed-status families. Nevertheless, more research with other transnational communities from the global south on the ways parent-child communication shifts during migration and separation and on if and how family relationships are reconstituted during migration would enhance the knowledge base about transnational family processes.

Although there are many questions about the internal dynamics of transnational and mixed-status families to investigate, this study sheds some light on family processes within Mayan families separated between the United States and Quiche, Guatemala, for an average of 
10 years. This study also suggests that consejos and other kinds of softer guidance from parents may be an important family process within transnational families when they cannot rely on face-to-face parent-child communication. Finally, this study shows how resilient Mayan transnational and mixed-status families can be to challenges of separation and of restrictive sociopolitical and economic conditions that may keep families divided by borders for many years to come.

\section{Note}

This research was supported by a grant from the American Association of University Women. I am grateful to the families who participated in this research and to M. Brinton Lykes, Cristina J. Hunter, and Ben Zion Hershberg for their comments on earlier versions of this manuscript.

\section{SUPPORTING INFORMATION}

Additional supporting information may be found in the online version of this article:

Appendix S1. Child Interview Guide in English and Spanish

\section{REFERENCES}

Bacigalupe, G., \& Lambe, S. (2011). Virtualizing intimacy: Information communication technologies and transnational families in therapy, Family Process, 50, 12-26. https://doi.org/10.1111/j .1545-5300.2010.01343.x

Becvar, D. S., \& Becvar, R. J. (2006). Family therapy: A systemic integration (6th ed.). Boston: Pearson Education.

Bornstein, M. H. (2012). Cultural approaches to parenting. Parenting, 12(2-3), 212-221. https://doi .org/10.1080/15295192.2012.683359.

Brabeck, K. M., Lykes, M. B., \& Hunter, C. (2014). The psychosocial impact of detention and deportation on US migrant children and families. American Journal of Orthopsychiatry, 84, 496-505. https://doi.org/10.1037/ort000001

Carey, D. (2001). Our elders teach us: Maya-Kaqchikel historical perspectives. Birmingham, AL: University of Alabama Press.

Castañeda, E. (2012). Living in limbo: Transnational households, remittances and development. International Migration, 50(S1), 13-35. https://doi.org/ 10.1111/j.1468-2435.2012.00745

Charmaz, K. (2006). Constructing grounded theory: A practical guide through qualitative analysis. Thousand Oaks, CA: SAGE.

Coutin, S. B. (2000). Legalizing moves: Salvadoran immigrants' struggle for U.S. residency. Ann Arbor, MI: University of Michigan Press.
Delgado-Gaitan, C. (1994). Consejos: The power of cultural narratives. Anthropology \& Education Quarterly, 25, 298-316. https://doi.org/10.1525/ aeq.1994.25.3.04x0146

Didkowsky, N., Ungar, M., \& Liebenberg, L. (2010). Using visual methods to capture embedded processes of resilience for youth across cultures and contexts. Journal of the Canadian Academy of Child and Adolescent Psychiatry, 19(1), 12-18.

Dreby, J. (2010). Divided by borders: Mexican migrants and their children. Berkeley, CA: University of California Press.

Grandin, G., Levenson, D., \& Oglesby, E. (2011). The Guatemala reader: History, culture, politics. Durham, NC: Duke University Press.

Grotevant, H., \& Cooper, C. (1998). Individuality and connectedness in adolescent development: Review and prospects for research on identity, relationships, and ethnic discrimination and ethnic identification. In E. Skoe \& A. von der Lippe (Eds.), Personality development in adolescence: A cross national and life span perspective (pp. 3-37). Florence, KY: Taylor \& Francis/Routledge.

Hagan, J., Eschbach, K., \& Rodriguez, N. (2008). U.S. deportation policy, family separation, and circular migration. International Migration Review, 42, 64-88. https://doi.org/10.1111/j.1747-7379 .2007.00114.x

Hershberg, R. M., \& Lykes, M. B. (2015). Transnational mixed-status families. In A. Sheuths \& J. Lawston (Eds.). Living together, living apart: Mixed status families and US immigration policy (pp. 37-53). Seattle: University of Washington Press.

Horton, S. (2009). A mother's heart if weighed down with stones: A phenomenological approach to the experience of transnational motherhood. Culture, Medicine, Psychiatry, 33, 21-40. https://doi.org/10 $.1007 / \mathrm{s} 11013-008-9117-\mathrm{z}$

Jerves, E., De Haene, L., Enzlin, P., \& Rober, P. (2016). Adolescents' lived experiences of close relationships in the context of transnational families: A qualitative study from Ecuador. Journal of Adolescent Research. Advance online publication. https://doi.org/10.1177/0743558416664027

Krogstad, A. D. (2015). Grandmothers, earth, and corn: The Maya woman in the work of Calixta Gabriel Xiquín. The Latin Americanist, 59, 47-60. https://doi.org/10.1111/tla.12047

López, G., \& Vázquez, V. (2006). Parental involvement in Latina/Latino-impacted schools in the Midwest: Recognizing the role and function of home-based knowledge and practices. Journal of School Public Relations, 27, 365-396.

LaRossa, R. (2005). Grounded theory methods and qualitative family research. Journal of Marriage and Family, 67, 837-857. https://doi.org/10.1111/ j.1741-3737.2005.00179.x 
Loucky, J. (2012). Continental contours of Maya migration over thirty years. Practicing Anthropology, 34, 4-8. https://doi.org/10.17730/praa.34 .1.n6u451640j376027

Lykes, M. B., \& Hershberg, R. M. (2015). Continuities and discontinuities in human rights violations: Historically situating the psychosocial effects of migration. Journal of Social Issues, 71, 244-263. https://doi.org/10.1111/josi.12108

Mazzucato, V., \& Schans, D. (2011). Transnational families and the well-being of children: Conceptual and methodological challenges. Journal of Marriage and Family, 73, 704-712. https://doi .org/10.1111/j.1741-3737.2011.00840.x

Menjívar, C., \& Abrego, L. (2009). Parents and children across borders: Legal instability and intergenerational relations in Guatemalan and Salvadoran families. In N. Foner (Ed.), Across generations: Immigrant families in America (pp.160-189). New York: New York University Press.

Mills, J., Bonner, A., \& Francis, K. (2006). Adopting a constructivist approach to grounded theory: Implications for research design. International Journal of Nursing Practice, 12, 8-13. https://doi.org/10 $.1111 /$ j.1440-172X.2006.00543.x

Montes, V. (2013). The role of emotions in the construction of masculinity: Guatemalan migrant men, transnational migration, and family relations. Gender \& Society, 27, 469-490. https://doi.org/10 $.1177 / 0891243212470491$

Morrow, S. (2005). Quality and trustworthiness in qualitative research in counseling psychology.
Journal of Counseling Psychology, 52, 250-260. https://doi.org/10.1037/0022-0167.52.2. 250

Parreñas, R. (2005). Children of global migration. Transnational families and gendered woes. Stanford, CA: Stanford University Press.

Sørensen, N. N., \& Vammen, I. M. (2014). Who cares? Transnational families in debates on migration and development. New Diversities, 16, 89-108.

Strauss, A., \& Corbin, J. (1998). Basics of qualitative research: Techniques and procedures for developing grounded theory (2nd ed.). Thousand Oaks, CA: SAGE.

Váldes, G. (1996). Con respecto: Bridging the distance between culturally diverse families and schools: An ethnographic portrait. New York: Teachers College Press.

Xiquín, C. G. (2008). La cosmovisión maya y las mujeres: Aportes desde el punto de vista de una ajq'ij (guía espiritual) kaqchikel [The Maya worldview and women: Contributions from the point of view of an ajq 'il (spiritual guide) kaqchikel]. Guatemala: Ministerio de Cultura y Deportes, Editorial Cultura.

Zentgraf, K., \& Stoltz Chinchilla, N. (2012). Transnational family separation: A framework for analysis. Journal of Ethnic and Migration Studies, 38, 345-366. https://doi.org/10.1080/1369183X.2011 .646431 .

Zhao, F., \& Yu, G. (2016). Parental migration and rural left-behind children's mental health in China: A meta-analysis based on mental health test. Journal of Child and Family Studies, 25, 3462-3472. https://doi.org/10.1007/s10826-016-0517-3. 